\title{
AUTHOR INDEX VOLUME 6 (1996)
}

Ahmad, M. O., see Shi, Y.-H.

Ahmadi, M., see Cao, J.

Akers, L. A., see Wang, T.

Alexiou, G., see Deliyannis, T.

Ashur, A. S., see Mekhallalati, M. C.

Ball, C. F. and Mlynski, D. A., Fuzzy Bi- and Multi-Partitioning for Circuits Represented by Hypergraphs

Baqai, F. A., Hua, Y.-B. and Yang, H., Matrix Pencil Methods for 2-D Frequency Estimation

Bashagha, A. E. and Ibrahim, M. K., Nonrestoring Radix-2 ${ }^{k}$ Square Rooting Algorithm

Berkovich, S. Y. and Chang, L.-C., A Multiprocessor Network Arranging Replicated Objects in Pairwise Balanced Combinatorial Designs

Cairns, G. and Tarassenko, L., Perturbation Techniques for On-Chip Learning with Analogue VLSI MLPs

Cao, J., Ahmadi, M., and Shridhar, M., Handwritten Numeral and Machine Printed Multiple Font Character Recognition Using Neural Network Classifier

Card, H., Ultrahigh Density VLSI Inner Product Computations

Carlson, B. S., see Hu, Y.

Cel, J., A Converse of Dual Tellegen's Theorem

Chang, L.-C. see Berkovich, S. Y.

Chatterji, B. N., see Das, B. K.

Chen, D.-S., Sarrafzadeh, M., and Yeap, G. K. H., State Encoding of Finite State Machines for Low Power Design

Chua, L. O., see Wu, C. W.

Costiner, S., see Manolache, F. B.

Das, B. K., Mahapatra, R. N., and Chatterji, B. N., Performance Modeling of Discrete Cosine Transform for Star Graph Connected Multiprocessors

Deliyannis, T., Haritantis, I., Alexiou, G., Psychalinos, C., Limperis, A., and Layos, M., A New Method for SC Circuit

Synthesis Based on the Voltage Inversion Concept

Elmasry, M. I., see Zhang, D.

Er, M. H., see Jian, M.

Er, M. H., see Zhang, M.

Femia, N., Spagnuolo, G., and Tucci, V., Interval Analysis in Power Electronics
6 (1996) $429-434$

6 (1996) $569-580$

6 (1996) $155-169$

6 (1996) 15-39

6 (1996) 547-567

6 (1996) 503-526

6 (1996) $187-196$

6 (1996) $267-285$

6 (1996) 85-91

6 (1996) 93-113

6 (1996) 569-580

6 (1996) 537-546

6 (1996) 287-318

6 (1996) 425-428

6 (1996) 85-91

6 (1996) 635-648

6 (1996) 649-661

6 (1996) 227-241

6 (1996) 59-64

6 (1996) 635-648

6 (1996) 15-39

6 (1996) 79-84

6 (1996) 581-591

6 (1996) 607-618

6 (1996) 185 
Gao, S., see Kaufmann, M.

$6(1996) 1-13$

Gharbi, A. B. A. and Salam, F. M. A., Implementation and Experimental Results of a Chip for the Separation of Mixed and Filtered Signals

Gomez, G. and Siferd, R., An Adaptive Noise Canceler Implemented with CMOS Analog Technology

Goutis, C. E., see Kyriakis-Bitzaros, E. D.

Gregory, K. and Smith, I. R., An Electrical Analogue for a Gear Box

Gregory, K. and Smith, I. R., Mathematical Modelling of an Automatic Voltage Regulator

Haritantis, I., see Deliyannis, T.

Hayatleh, K., Lidgey, F. J., and Porta, S., Comparing Dual Current-Conveyor Configurations

$\mathrm{He}, \mathrm{Z}$., see Yao, S.

He, Z.-Y., see Shi, Y.-H.

Hess, H. L., see Wall, R. W.

$\mathrm{Hu}, \mathrm{Y}$. and Carlson, B. S., A Unified Algorithm for the Estimation and Scheduling of Data Flow Graphs

Hua, Y.-B., see Baqai, F. A.

Huelsman, L. P., see Oksasoglu, A.

Hwang, S. Y., see Kim, Y.-N.

Ibrahim, M. K., see Bashagha, A. E.

Ibrahim, M. K., see Mekhallalati, M. C.

Jian, M., Kot, A. C., and Er, M. H., Microphone Array System in Acoustical Source Localization Using Least Square Estimation

Kaufmann, M., Gao, S., and Thulasiraman, K., An Algorithm for Steiner Trees in Grid Graphs and Its Application to Homotopic Routing

Kim, Y.-N., Lee, H. D., and Hwang, S. Y., An Interconnect Allocation Algorithm for Performance-Driven Datapath Synthesis

Kot, A. C., see Jian, M.

Kyriakis-Bitzaros, E. D., Soudris, D. J., and Goutis, C. E., Transformation of Nested Loops into Uniform Recurrences and Their Mapping to Regular Processor Arrays

Layos, M., see Deliyannis, T.

Lee, H. D., see Kim, Y.-N.

Leung, F. H.-F., Wong, L.-K., and Tam, P. K.-S., A Simple Large-Signal Nonlinear Model for Zero-Current-Switch Quasi-Resonant Buck Converters

Lidgey, F. J., see Hayatleh, K.

Lienig, J. and Thulasiraman, K., GASBOR: A Genetic Algorithm Approach for Solving the Switchbox Routing Problem

Limperis, A., see Deliyannis, T.

Mahapatra, R. N., see Das, B. K.

Manolache, F. B., Sandu, D. D., and Costiner, S., Improved Microwave Selective Devices Using Weakly Asymmetric Resonant Cavities

Mekhallalati, M. C., Ashur, A. S., and Ibrahim, M. K., Radix Modular Multiplication Algorithm

6 (1996) 115-138

6 (1996) 139-154

6 (1996) 243-265

6 (1996) $73-77$

6 (1996) 65-72

6 (1996) 15-39

6 (1996) 475-484

6 (1996) 385-401

6 (1996) 429-434

6 (1996) 619-633

6 (1996) $287-318$

6 (1996) $187-196$

6 (1996) 197-212

6 (1996) 403-423

6 (1996) $267-285$

6 (1996) 547-567

6 (1996) 581-591

6 (1996) 1-13

6 (1996) 403-423

6 (1996) $581-591$

6 (1996) 243-265

6 (1996) 15-39

6 (1996) 403-423

6 (1996) 593-598

6 (1996) 475-484

6 (1996) 359-373

6 (1996) 15-39

6 (1996) 635-648

6 (1996) 59-64

6 (1996) $547-567$ 
Mikhael, W. B. and Yu, H., Adaptive, Frequency Domain, 2-D

Modeling Using Spatiotemporal Signals

6 (1996) $351-358$

Mikhael, W. B., see Ramaswamy, A.

Mlynski, D. A., see Ball, C. F.

Mohamed, K. A. and Pap, L., Performance Analysis of

Frequency-Hopped Spread-Spectrum Packet Radio Networks

Part II: Unslotted Multiple-Access

6 (1996) 41-57

6 (1996) 503-526

Mohamed, K. A. and Pap, L., Performance Analysis of

Frequency-Hopped Spread-Spectrum Packet Radio Networks

Part I: Slotted Multiple-Access

Murthy, K. V. V., see Pai, K. R.

Nishiyuki, H., see Urahama, K.

Nowrouzian, B., see Satyanarayana, J. H.

Oksasoglu, A. and Huelsman, L. P., State Feedback Filters

Ota, Y. and Wilamowski, B. M., CMOS Implementation of a Voltage-Mode Fuzzy Min-Max Controller

Pai, K. R., Murthy, K. V. V., and Ramachandran, V.,

Complementary Pole-Pair Filters and Pole-Parameter

Transformations

Pap, L., see Mohamed, K. A.

Pap, L., see Mohamed, K. A.

Park, K.-H., see Seo, K.-R.

Porta, S., see Hayatleh, K.

Prasad, V. C. and Rao Pinjala, S. N., A Fast Algorithm for Fault Isolation in Dictionary Approach of Analog Circuit Diagnosis

Psychalinos, C., see Deliyannis, $\mathrm{T}$.

Ramachandran, V., see Pai, K. R.

Ramaswamy, A. and Mikhael, W. B., Compression of Images Represented Using Multi-Transforms

Rao Pinjala, S. N., see Prasad, V. C.

Salam, F. M. A., see Gharbi, A. B. A.

Sandu, D. D., see Manolache, F. B.

Sarrafzadeh, M., see Chen, D.-S.

Satyanarayana, J. H. and Nowrouzian, B., Design and FPGA Implementation of Digit-Serial Modified Booth Multipliers

Seo, K.-R. and Park, K.-H., Task Assignment in Host-Satellite Systems

Shi, Y.-H., He, Z.-Y., Swamy, M. N. S., and Ahmad, M. O., A Method for Calculating the Radius of Convergence of an Equilibrium Point of a Continuous Feedback Neural Network

Shridhar, M., see Cao, J.

Siferd, R., see Gomez, G.

Smith, I. R., see Gregory, K.

Soudris, D. J., see Kyriakis-Bitzaros, E. D.

Spagnuolo, G., see Femia, N.

Srimani, P. K., see Vadapalli, P.

Swamy, M. N. S., see Shi, Y.-H.

Tam, P. K.-S., see Leung, F. H.-F.

Tan, E. C., Derivation of Similar Matrix of the Scattering Matrix for Numerical Computation in Electronic Networks

6 (1996) 453-474

6 (1996) 435-452

6 (1996) 319-350

6 (1996) $375-384$

6 (1996) 485-501

6 (1996) 197-212

6 (1996) 171-184

6 (1996) $319-350$

6 (1996) 435-452

6 (1996) 453-474

6 (1996) 213-225

6 (1996) 475-484

6 (1996) 663-670

6 (1996) 15-39

6 (1996) 319-350

6 (1996) 41-57

6 (1996) 663-670

6 (1996) 115-138

6 (1996) 59-64

6 (1996) 649-661

6 (1996) 485-501

6 (1996) 213-225

6 (1996) 429-434

6 (1996) 569-580

6 (1996) 139-154

6 (1996) 65-72

6 (1996) 243-265

6 (1996) 185

6 (1996) 527-536

6 (1996) 429-434

6 (1996) 593-598

6 (1996) 599-606 
Tarassenko, L., see Cairns, G.

Thulasiraman, K., see Kaufmann, M.

Thulasiraman, K., see Lienig, J.

Tucci, V., see Femia, N.

Urahama, K. and Nishiyuki, H., Performance of the Relaxation Algorithm for Maximum-Cut Problems

Vadapalli, P. and Srimani, P. K., Fault Tolerant Ring Embedding in Tetravalent Cayley Network Graphs

Wall, R. W. and Hess, H. L., Design and Microcontroller Implementation of a Three Phase SCR Power Converter

Wang, T. and Akers, L. A., An Electronic Habituation Chip

Wilamowski, B. M., see Ota, Y.

Wong, L.-K., see Leung, F. H.-F.

Wu, C. W., Zhong, G.-Q., and Chua, L. O., Synchronizing Nonautonomous Chaotic Systems Without Phase-Locking

Yang, H., see Baqai, F. A.

Yao, S. and He, Z., Analysis of Multicomponent Chirp Signals Using Frequency-Shear Representation

Yeap, G. K. H., see Chen, D.-S.

Yu, H., see Mikhael, W. B.

Zhang, D. and Elmasry, M. I., A Digital Perceptron Learning Implementation with Look-Up Table Feedback Layer

Zhang, M. and Er, M. H., Calibration of Sensor Channel Delay

Uncertainties for Linear Microphone Arrays in Far Field

Zhong, G.-Q., see Wu, C. W.
6 (1996) 93-113

6 (1996) $1-13$

6 (1996) 359-373

6 (1996) 185

6 (1996) $375-384$

6 (1996) $527-536$

6 (1996) 619-633

6 (1996) $155-169$

6 (1996) 171-184

6 (1996) $593-598$

6 (1996) 227-241

6 (1996) $187-196$

6 (1996) 385-401

6 (1996) 649-661

6 (1996) 351-358

6 (1996) $79-84$

6 (1996) 607-618

6 (1996) $227-241$ 